\title{
Evaluation on the Stability of Muddy Tidal Flat
}

\author{
Zhiyi Lei ${ }^{1, a^{*}}$, Xuesong Zhang ${ }^{1, b}$ \\ ${ }^{1}$ College of Harbour, Coastal and Offshore Engineering, Hohai University, Nanjing, China \\ alei_zhiyi@hhu.edu.cn, bjobzhxs@sina.com
}

Keywords: Muddy tidal flat, Stability, Indicator system, Evaluation

Abstract. Based on the field hydrology test, topographic map, remote sensing data and cross section survey data, the influence factors and the degree of the muddy tidal flat in Jiangsu coast area are studied, and the stability criterion for determining the stability of the three stages is established. The stability of the tidal flat in Jiangsu Province between Wanggang and Chuandonggang is judged to be in a state of deposition that is in agreement with the actual situation.

\section{Introduction}

Muddy tidal flat is distributed in the coastal intertidal zone composed of fine sediment. With special environment, rich resources and diverse types, muddy tidal flat impacts on the natural environment and social economic development. It can promote beach silting up, to provide more land resources; deep tidal channel between flat and bars can be potential port resource; tidal flat possesses greatly rich biological diversity and so on [1-3].

The tidal flat area of Jiangsu Province has a vast area, with abundant tidal flat resources around the ridge. The total area of $5001.68 \mathrm{~km}^{2}$, is about $1 / 4$ of the total tidal flat area of the nation.

By 2020 there will be $1800 \mathrm{~km}^{2}$ reclamation are from Sheyang Estuary to Dongzhao Port, by 2050 there will be $4667 \mathrm{~km}^{2}$ reclamation area as reserve land [4]. To achieve this goal, the height of the surrounding area is reduced to the $2 \mathrm{~m}$ above the lowest level of the theory by traditional mean high tide line in the national planning, which is located in coastal salt marshes of the outer edge of the line.

Obviously it's important for coast development and coastal engineering to study the stability of muddy tidal flat and establish an indicator system.

\section{Stability factors of muddy tidal flat}

Muddy tidal flat is about $1 / 4$ of the total coastline of the mainland in China, which is mainly distributed in the Yangtze River, the Yellow River, Pearl River, Liaohe River, and other coastal areas along the coast of Zhejiang Province, Fujian Province, Guangdong Province and Guangxi Province. The stability of the muddy tidal flat is mainly influenced by the topography, the coastal power and the human activities [5].

Influence of the tidal channel system. Coastal tidal channel system is one of the main factors led to the tidal flat erosion and deposition. For the broad tidal flat, dendritic tidal creek system usually developed, and presents periodic oscillation phenomenon; for narrow tidal flat, the tidal creek is usually short and the beach is broken; for the near shore sandbars, they usually grow parallel to the tidal channels, and adjacent tidal creek system. The changing trend of the same scale tidal channel system is the key factor for the stability of the tidal flat.

Effect of sand ridges. The coastal area of Jiangsu Province is mainly affected by the tidal wave system of East China Sea and the rotary tidal wave system of South Yellow Sea. Hydrodynamic condition of the area is complex and underwater terrain is changeable. The characteristics of the special muddy tidal flat and radial sand ridges are formed under the unique water and sediment dynamics, and the dynamic geomorphology is an important factor for the stability of the muddy tidal flats.

Effect of coastal beach reclamation. Jiangsu Province has a long history of coastal reclamation. From 1951 to 2007 there are 203 reclamation zones with total area of $268.7 \times 10^{3} \mathrm{hm}^{2}$. The stability of coastal tidal flat is influenced by the reclamations, and it's imperative to understand the reclamation 
potential by studying water and sediment dynamic, the characteristics of the coastal development and the economic development conditions.

\section{Indicator system of the stability of muddy tidal flat}

The stability of muddy tidal flat is involved in many factors, but too many indexes will disturb the work. A few of the most accurate indicators can be screened out from these numerous evaluation indicators.

Topography and geomorphology, like the length, depth, direction, area of the tidal creek system; as well as the beach width, slope, sediment composition and coastal salt marsh area and distribution features.

Coastal power is an indispensable factor in the formation of shore beach that should be considered such as wave, tide, extreme weather (typhoon) and suspended sediment.

In recent years, human activities have gradually increased the impact of the stability of the tidal flat, especially reclamation engineering and coastal aquaculture activities, which should be considered.

Classification of the stability of muddy tidal flats. Referring to the standard of the stability of tidal flat, the stability of the muddy tidal flat is divided into three levels: deposition, stability and erosion. The correlation threshold of each index is shown in Table 1.

Table 1. Indicator system of stability of muddy tidal flat

\begin{tabular}{|c|c|c|c|c|c|}
\hline \multirow{2}{*}{ No. } & \multirow{2}{*}{ Indicator } & \multicolumn{3}{|c|}{ Classification of the stablility } & \multirow{2}{*}{$\begin{array}{l}\text { Score of the } \\
\text { research area }\end{array}$} \\
\hline & & Deposition & Stability & Erosion & \\
\hline 1 & Tidal creek lenth & $>5 \mathrm{~km}$ & $2-5 \mathrm{~km}$ & $<2 \mathrm{~km}$ & 0.029 \\
\hline 2 & Tidal creek width & Arborization & Single & Small & 0.027 \\
\hline 3 & $\begin{array}{l}\text { Tidal creek area/tidal basin } \\
\text { area }\end{array}$ & $>10 \%$ & $4 \%-10 \%$ & $<4 \%$ & 0.051 \\
\hline 4 & Beach width & $>3 \mathrm{~km}$ & $1-3 \mathrm{~km}$ & $<1 \mathrm{~km}$ & 0.026 \\
\hline 5 & Beach slope & $<0.5 \%$ & $0.5 \% o-0.8 \% o$ & $>0.8 \% 0$ & 0.046 \\
\hline 6 & Feature of bars & $\begin{array}{l}\text { Combination of } \\
\text { small bars }\end{array}$ & $\begin{array}{l}\text { No obvious } \\
\text { change }\end{array}$ & $\begin{array}{l}\text { Division from big } \\
\text { bars }\end{array}$ & 0.042 \\
\hline 7 & Salt marsh area ratio & $>30 \%$ & $10 \%-30 \%$ & $<10 \%$ & 0.035 \\
\hline 8 & Distribution of salt marsh & Parallel to & Patch shape & Scattered & 0.026 \\
\hline 9 & Often wave direction & NNE & ENE & $\mathrm{NE}$ & 0.037 \\
\hline 10 & Average wave height & $>3 \mathrm{~m}$ & $0.7 \sim 2.0 \mathrm{~m}$ & $0.4 \sim 0.6 \mathrm{~m}$ & 0.042 \\
\hline 11 & Vertical mean flow rate & $>1.0 \mathrm{~m} / \mathrm{s}$ & $0.6 \sim 1.3 \mathrm{~m} / \mathrm{s}$ & $0.3 \sim 0.5 \mathrm{~m} / \mathrm{s}$ & 0.023 \\
\hline 12 & Maximum flow rate & $>2 \mathrm{~m} / \mathrm{s}$ & $1.2 \sim 1.5 \mathrm{~m} / \mathrm{s}$ & $<1.0 \mathrm{~m} / \mathrm{s}$ & 0.037 \\
\hline 13 & Flow direction & Reciprocating flow & $\begin{array}{l}\text { Reciprocating } \\
\text { flow }\end{array}$ & Rotating flow & 0.037 \\
\hline 14 & Mean tidal range & $6.0 \sim 7.0 \mathrm{~m}$ & $3.0 \sim 3.5 \mathrm{~m}$ & $2.0 \sim 3.0 \mathrm{~m}$ & 0.038 \\
\hline 15 & Typhoon frequency & $<1$ & $1 \sim 2$ & $>4$ & 0.024 \\
\hline 16 & $\begin{array}{l}\text { Average vertical sediment } \\
\text { amount }\end{array}$ & $1.0 \sim 1.2 \mathrm{~kg} / \mathrm{m}^{3}$ & $0.2 \sim 1.0 \mathrm{~kg} / \mathrm{m}^{3}$ & $<0.1 \mathrm{~kg} / \mathrm{m}^{3}$ & 0.042 \\
\hline 17 & $\begin{array}{l}\text { Measured maximum } \\
\text { sediment amount of rising } \\
\text { tide }\end{array}$ & $2.3 \sim 3.5 \mathrm{~kg} / \mathrm{m}^{3}$ & $1.0 \sim 2.2 \mathrm{~kg} / \mathrm{m}^{3}$ & $<1.0 \mathrm{~kg} / \mathrm{m}^{3}$ & 0.029 \\
\hline 18 & $\begin{array}{l}\text { Measured maximum } \\
\text { sediment amount of falling } \\
\text { tide }\end{array}$ & $3.5 \sim 4.5 \mathrm{~kg} / \mathrm{m}^{3}$ & $1.3 \sim 3.4 \mathrm{~kg} / \mathrm{m}^{3}$ & $<1.2 \mathrm{~kg} / \mathrm{m}^{3}$ & 0.032 \\
\hline 19 & Reclamation layout & Massive block & $\begin{array}{l}\text { Small area along } \\
\text { the bank }\end{array}$ & Offshore & 0.035 \\
\hline 20 & Reclamation range & Supratidal zone & Intertidal zone & Subtidal zone & 0.071 \\
\hline 21 & Reclamation area & $>5 \mathrm{~km}^{2}$ & $3-5 \mathrm{~km}^{2}$ & $<3 \mathrm{~km}^{2}$ & 0.022 \\
\hline & & & & Total score & 0.751 \\
\hline
\end{tabular}




\section{Fuzzy Assessment for Stability of Muddy Tidal Flat}

Assessment for stability of muddy tidal flat is a multi-objective multi-level evaluation process. The indicator system includes not only quantitative indicators but also qualitative indicators. The pros and cons of the object have not absolute boundaries during the recognition process, which belongs to fuzzy concept, so the fuzzy identification method is employed here [6].

Standard Eigen value. There are $\mathrm{n}$ things to identify an estuarine wetland $\mathrm{A}$, and the set is $X=\left\{x_{1}, x_{2}, \mathrm{~L}, x_{n}\right\}$. Each thing can be described by $\mathrm{m}$ indicator eigen values $x_{j}=\left(x_{1 j}, x_{2 j}, \mathrm{~L}, x_{m j}\right)^{T}$.

So the set $X$ is a $m \times n$ matrix of indicator eigen values. According to the indicator standard eigen values of $c$ grades to identify, there is a matrix of standard eigen values $Y=\left(y_{i h}\right)$, in which $y_{i h}$ is the standard eigen value of indicator $i$ in grade $\mathrm{h}, h=1,2, \ldots, c$.

Relative Membership. There are generally two types of indicator. Type I: the standard eigen value $y_{i h}$ decreases with the increase of grade $h$. Type II: the standard eigen value $y_{i h}$ increases with the grade $h$.

As for the indicators of type I, make the relative membership to wetland $A$ equal to 0 , if those indicators less than or equal to the standard eigen value of grade $c$. And make the relative membership equal to 1 , if those indicators more than or equal to the standard eigen value of grade $c$. The intermediate states should be linear. So the relative membership of indicator of type I and II can be expressed and similarly the relative membership of $y_{i h}$ to A can be expressed also.

Then the membership matrix of the indicators is $R=\left(r_{i j}\right)_{m \times n}$, and the membership matrix of the standard eigenvalue is $S=\left(s_{i h}\right)_{m \times c}$. The formulas (1) (4) are the relative membership functions.

The Weights of the Indicators. The weights can be expressed as $W=\left(w_{1}, w_{2}, \mathrm{~L}, w_{n}\right)$. The AHP method and expert method are used here to get the weights of indicators. After being normalized, the weights can be written as $\sum_{i=1}^{n} w_{i}=1 \quad\left(w_{i} \geq 0, i=1,2, \mathrm{~L}, n\right)$.

Fuzzy Recognition. Comparing respectively the relative membership $r_{j}=\left(r_{1 j}, r_{2 j}, \mathrm{~L}, r_{m j}\right)^{T}$ in matrix $R$ with the row vector in matrix $S$, we can get the upper limit $b_{j}$ and lower limit $a_{j}$ of grade of the thing $j$. Suppose the relative membership matrix is written as $\sum_{h=a_{j}}^{b_{j}} u_{h j}=1$, in which $u_{h j}$ is the membership of the thing $j$ to grade $h, j=1,2, \ldots, n ; h=1,2, \ldots, c$. If the weights of indicator $i$ are the same, and with the condition $\sum_{i=1}^{m} w_{i}=1$, the weights can be expressed as $w=\left(w_{1}, w_{2}, \mathrm{~L}, w_{n}\right)$. Then the Weighted generalized distance from $j$ to $h$ can be written as $d_{h j}=\left|\sum_{i=1}^{m}\left[w_{i} \cdot\left(r_{i j}-s_{i h}\right)\right]^{p}\right|^{\frac{1}{p}}$, in which $p$ is the distance parameter. In order to get the optimal relative membership of $j$ to $h$, the objective function is $\min \left|F\left(u_{i j}\right)=\sum_{h=a_{j}}^{b_{j}} D_{h j}^{2}\right|$. Then a lagrange function is constructed as $L\left(u_{h j}, \lambda_{j}\right)=\sum_{h=a_{j}}^{b_{j}} u_{h j}^{2} \cdot d_{h j}^{2}-\lambda_{j} \cdot\left|\sum_{h=a_{j}}^{b_{j}} u_{h j}-1\right|$, in which $\lambda_{j}$ is the Lagrange multiplier. Then the complete fuzzy recognition model can be written as eq.1.

$$
u_{h j}= \begin{cases}0, & h<a_{j} \text { or } h>b_{j} \\ \left|d_{h j}^{2} \cdot \sum_{k=a_{j}}^{b_{j}} d_{k j}^{-2}\right|^{-1}, & d_{h j} \neq 0, a_{j} \leq h \leq b_{j} \\ 1, & d_{h j}=0 \text { or } r_{i j}=s_{i h}\end{cases}
$$




\section{Application of the evaluation model}

Take the coastal area between Wanggang and Chuandonggang in Jiangsu Province for example to test this model. This shore segment orients open sea, nearly NS to extend. The tidal flat width is about $2.5 \mathrm{~km}$ with straight shoreline and gentle slope, average slope of about $0.4 \%-0.5 \%$, and the profile is convex. The waters where regular semidiurnal tide with mean high tide level about $1.99 \mathrm{~m}$, mean low tide of $-1.07 \mathrm{~m}$, and mean tidal range of $3.06 \mathrm{~m}$. The maximum tidal range is about $4.65 \mathrm{~m}$, the minimum one is 1.57 , the measured maximum tidal level is $3.75 \mathrm{~m}$, and the measured lowest tide level is $-1.64 \mathrm{~m}$. The average high tide lasts $5 \mathrm{~h} 07 \mathrm{~m}$, and the mean ebb tide lasts $7 \mathrm{~h} 18 \mathrm{~m}$. The tidal wave in the area is standing waves, and the forward wave characteristic is not obvious. Reciprocating flow is normal, with flood tide direction of SSE, ebb tide direction of NNW. This area is a strong tidal zone with mean flood flow velocity of $0.80 \sim 1.29 \mathrm{~m} / \mathrm{s}$ and the mean ebb flow rate of $0.88 \sim 1.50 \mathrm{~m} / \mathrm{s}$. Suspended sediment concentration is large, the vertical average sediment amount is $1.50 \mathrm{~kg} / \mathrm{m}^{3}$ of spring tide, and is 0.70 $\mathrm{kg} / \mathrm{m}^{3}$ in neap period.

Since the 1980 s of the 20 th century, the reclamation area is totally about $163 \mathrm{~km}^{2}$, which is mainly used for the development of aquaculture, planting and wind power projects.

The total score can show the stability of the research area. Index can get 0.8 when it is in arrange of "deposition", get 0.5 in the "stability" and get 0.2 in "erosion". By multiplying the index value and weight, the total score of was obtained in Table 1 , and the total score of the tidal flat was 0.751 (between 0.7 and 1) which indicate the area is in a state of "deposition", that is in agreement with the actual situation .

\section{Conclusion}

Establishing an assessment system of estuarine wetland health is an important aspect of wetland protection and research. And a feasible system is established in this paper based on the PSR framework. Using the fuzzy recognition method, several indicators are chosen to evaluate three wetlands in the Yangtze River Estuary. This assessment system is feasible.

\section{Acknowledgment}

This research is financially supported by the National Natural Science Foundation of China, "Study on Wetland Area Holdings With No Ecology Function Loss" (Grant No. 51409088 ).

\section{References}

[1] Harris, P.T., Pattiaratchi, C.B., Cole, A.R. and Keene, J.B., 1992, Evolution of subtidal sandbanks in Moreton Bay, eastern Australia, Marine Geology, 103: 225-247.

[2] Liu, Z.X., 1997, Yangtze Shoal-a modern tidal sand sheet in the northwestern part of the East China Sea, Marine Geology, 137: 321-330.

[3] Carbajal, N. and Y. Montaňo, 2001. Comparison between predicted and observation physical features of sandbanks, Estuarine, Coastal and Shelf Science, 52: 435-443.

[4] The outline of the plan for the development and utilization of coastal land reclamation in Jiangsu. Jiangsu Provincial Development and Reform Commission. 2012.

[5] Zhiyi Lei, Jinshan Zhang. Numerical Simulation of Water Level under Interaction between Runoff and Estuarine Dynamics in Tidal Reach of the Yangtze River. China Ocean Engineering. 2009,(3):543-551.

[6] Tu Xiangyang, Gao Xueping. Application of fuzzy mathematical method in evaluation of seawater intrusion, Journal of hydraulic engineeing, 2013. (In Chiese) 